\title{
The Propagation of Wireless Waves of Short Wave-length round the World.
}

\section{By Dr. J. A. Fleming, F.R.S.}

$\mathrm{Q}^{\mathrm{u}}$

UITE the most important of the pronouncements of the past year in connexion with wireless telegraphy were the two addresses given by Senatore Marconi to the Royal Society of Arts, London, in July and December, and also a paper by Sir Joseph Larmor, in NATURE of November I, and the Philosophical Magazine for December last, on the theory of wireless transmission round the world. Senatore Marconi gave details in July of his remarkable achievements with electric waves of relatively short wave-length, and in December of his discovery that waves of only 30 metres in length, or about roo ft., can be used for reliable communication by day as well as by night over any distance, even to the antipodes, although entire continents and mountain ranges intervene (see NATURE, September 6, p. 359, and December 27, p. 939). In this most important advance, he has certainly priority of achievement, as he had in I9or, in long-wave transmission across the Atlantic. When in I902 Senatore Marconi discovered the great difference in range between day and night transmission with long waves across the Atlantic, it at once became clear that wireless transmission involved not only the ether of space round the earth, but also that the atmosphere itself, and especially, its state as regards illumination by sunlight, had a great deal to do with the matter.

In the years that followed, radio engineers came to the conclusion that the best prescription for achieving regular commercial radiotelegraphy at all times of day and night over long world-distances was by increasing the wave-length and power. Hence between 1902 and 1922 the demand for long distance radiotelegraphy involved the erection of large high-power all-round stations with great aerials sending out electric waves 30,000 to $60,000 \mathrm{ft}$. in wave-length, and using power from 500 to 1500 horse-power or more. The latest example is the Iooo-kilowatt British Government radio station now being erected at Rugby.

The inhabited land area of the world being chiefly confined to one-half of the terrestrial globe, and the useful long wave-lengths being included within somewhat narrow limits, it is clear there is not an unlimited possibility of putting up all-round super-power radio stations without risk of interference.

Accordingly, so far back as rgr6, Senatore Marconi began to consider the alternative of exploring the utility of the other extremity of the wireless spectrum or gamut of wave-lengths, and using waves more nearly 100 to $300 \mathrm{ft}$. in wave-length projected as a beam by skeleton parabolic mirrors of vertical wires. It was well understood that when using such mirrors, the wavelength employed must be less than the aperture and height of the mirror, and constructive difficulties placed a limit on the mirror dimensions. Hence for beam projection short wave-lengths were essential. In r9r6, experiments were conducted by Marconi in Italy with suchshort-wave beam radiotelegraphy for war purposes; and later in England, with the able assistance of $\mathrm{Mr}$. C. S. Franklin, important results were obtained in radiotelephony by 15 -metre waves between London and Birmingham. The achievements between I9I6 and 1922 described in published papers by Senatore
Marconi and Mr. Franklin in 1922, amply demonstrated the practical value of these short waves of roo-metre wave-length or less. In I923, a series of tests by Marconi and his assistants on his yacht over long world-distances showed that communication could be established by these waves from Poldhu to Australia, but that the Ioo-metre wave had a markedly greater range by night than by day.

In October of 1924, Marconi discovered that the daylight range increased very rapidly as the wavelength was reduced from roo to 32 metres, or say from 300 to roo ft. ; and that perfect communication could be established for all hours of the day and night between England and Australia by the $3^{2-m e t r e ~ w a v e ~}$ when using only Io or I 2 kilowatts (say 15 h.-p.) in the transmitter.

Apart altogether from the immense practical importance of this discovery, it raises scientific questions of high interest as to the mechanism by which these waves travel round the world. It is now quite clear that normal wave diffraction is not sufficient. The signal strengths at large world-distances are thousands of times greater than they could be by mere diffraction. It is generally agreed that the effect must be due in some way to ionisation of the high-level atmosphere, which descends to a lower level during the day-time. Although many theories have been put forward, the important paper by Sir Joseph Larmor, above mentioned, throws fresh light on the subject. When an electric wave passes through ionised air it sets the ions in vibration. If the ions collide at once with gas molecules, energy is dissipated and the wave is weakened.

If the mean free path of the ion is long (say ro times) compared with the distance the ion is moved by the wave in the periodic time of the wave, then there will not be much dissipation of energy but the effective dielectric constant of the medium will be reduced and the wave velocity increased.

Larmor shows that at a certain height in the atmosphere, there is a region in which this accelerated and slightly dissipated wave energy can travel, and that a comparatively small ionic density will be effective. His equations show that the increase in wave speed depends on the ionic density and the square of the wave-length, and the modulus of absorption of the wave energy on the product of the ionic density and wave-length.

The increase in speed of the upper part of the wave front causes the wireless ray to curve round the earth, and Larmor specifies the conditions which must be fulfilled for the required curvature to be produced.

It appears, then, that for a given ionic density the long waves are more absorbed than the short, but the long waves have more energy at starting. Each wireless ray has its own proper path in the ionised air in travelling from the transmitter to any receiver. The shorter waves travel at a higher level in the atmosphere where the ionic density is greater and more constant, and this compensates for the smaller wavelength in giving the required ray curvature and makes them less affected by day and night variations. The 
longer waves travel chiefly in a region in which the ionic density varies very much between day and night and are thus less absorbed by night.

In a general way, therefore, the theory fits in with facts, but there are an immense number of well-known wireless wave effects which will require consideration and discussion before we can say we can account for them all on any theory. Meanwhile, the practical consequences of the discovery of the properties of this $3^{2}$-metre wave are very great.

Is there, for example, any justification for creating new high-power all-round radio stations by which the communication is. so to speak, bellowed over the world on 20,000-metre waves, when on the beam system perhaps a dozen stations could be erected for the same capital and annual working cost, which would whisper their message on 32-metre waves along limited paths, taking up much less room in the ether? Time, and perhaps expensive experience, will show whether the all-round high-power station is necessary. In any event, the short-wave system has the enormous advantage that the receiving appliances used in connexion with it are vastly more immune from atmospheric disturbances and render all-day and all-night intercommunication possible over long distances, even up to the antipodes.

\section{The Oldest Fossil Fishes.}

\section{By Sir ARThur Smith Woodward, F.R.S.}

$\mathrm{T}$ has long been known that the fishes of the Downtonian age-the earliest fishes of which we have any real knowledge-are very different from those which appeared in later times and persist in part to the present day. Prof. Johan Kiær, of the University of Christiania, discovered fossil fishes in the rocks of this period in southern Norway a few years ago, and the first part of his memoir describing them has recently been issued. ${ }^{1}$ Prof. Kixr's remarkable specimens add

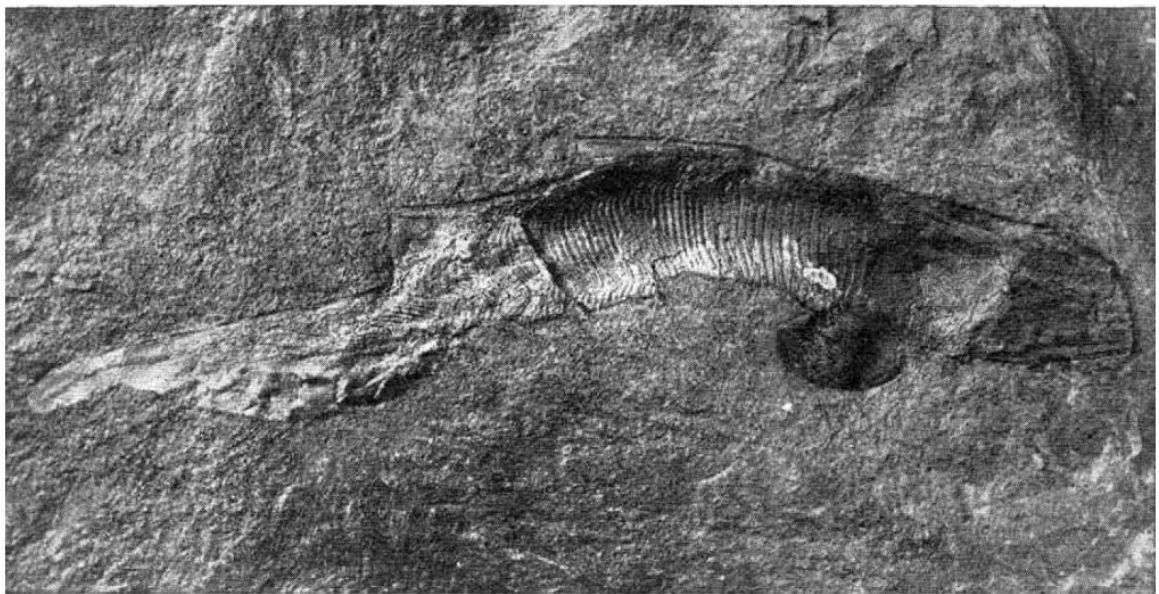

FIG. I.-Aceraspis robustus, Kiær. Nearly complete specimen, nat. size. The foremost part of the head is incomplete. From "The Downtonian Fauna of Norway." these.

all are as usual small, none being more than two decimetres in length. The most striking novelties are referable to the Anaspida--laterally compressed fusiform fishes which were first described by the late Dr. R. H. Traquair from the Downtonian rocks of southern Scotland-and Prof. Kiær begins by devoting attention to the three new genera which he finds among

In the original Scottish specimens, Dr. Traquair was unable to make out any definite features in the head, and until he obtained examples with the heterocercal (or primitive unequal-lobed) tail, he felt uncertain as to which were the dorsal and ventral borders respectively. In the new Norwegian specimens Prof. Kiær has been more fortunate in finding both the head and the tail well preserved, and it now appears that the Anaspida differ from all other known heterocercal fishes in having the tapering end of the body bent downwards instead of upwards (see Fig. 2). Dr. Traquair indeed

greatly to our knowledge of these fishes, and some of his conclusions are so unexpected that they are of extreme interest to both zoologists and geologists.

It appears that the Downtonian rocks of the Christiania region closely resemble those of Great Britain, and similarly contain the fishes in association with crustaceans and eurypterids in a good state of preservation. They are shallow water deposits, with frequent traces of ripple marks and sun cracks, and Prof. Kiær thinks they must have been formed in freshwater lakes on flood-plains. Some of the fishes are familiar, such as the beautiful Cephalaspidian reproduced in Fig. I, which differs little from Cephalaspis itself except in having two dorsal fins instead of the single one. All, indeed, belong to known groups, and 1 The Downtonian Fauna of Norway. I. Anaspida, with a Geological Introduction. By Johan Kiær. Vidensk. Skrift. I. Mat.-naturv. Kl. 1924, No. 6. Kristiania, I924. described all his specimens upside down. We have for the first time among fishes a form of tail which is known among the extinct marine reptiles, the ichthyosaurs, mosasaurs, and certain Jurassic crocodiles. Prof. Kiær, following Schmalhausen, supposes that this arrangement is correlated with the position of the centre of gravity of the fish.

The roof of the skull, which led to the discovery of the anomaly in the tail, is also very interesting. So far as it affords a clue to the underlying soft parts, it agrees with the cranial roof in the contemporary and allied cephalaspidians. As shown in Prof. Kiær's outline restorations (Fig. 3), the large orbits are distinct, not far apart, and each is surrounded by a hard rim. Between them is a plate pierced by a perforation doubtless for the pineal body; and immediately in front of this is a larger median perforation which may 